\title{
Distractor interference in selective reaching: dissociating distance and grouping effects
}

Citation for published version (APA):

Keulen, R. F., Adam, J. J. M. E., Fischer, M. H., Kuipers, H., \& Jolles, J. (2003). Distractor interference in selective reaching: dissociating distance and grouping effects. Journal of Motor Behavior, 35(2), 119-126. https://doi.org/10.1080/00222890309602127

Document status and date:

Published: 01/01/2003

DOI:

10.1080/00222890309602127

Document Version:

Publisher's PDF, also known as Version of record

\section{Please check the document version of this publication:}

- A submitted manuscript is the version of the article upon submission and before peer-review. There can be important differences between the submitted version and the official published version of record.

People interested in the research are advised to contact the author for the final version of the publication, or visit the DOI to the publisher's website.

- The final author version and the galley proof are versions of the publication after peer review.

- The final published version features the final layout of the paper including the volume, issue and page numbers.

Link to publication

\footnotetext{
General rights rights.

- You may freely distribute the URL identifying the publication in the public portal. please follow below link for the End User Agreement:

www.umlib.nl/taverne-license

Take down policy

If you believe that this document breaches copyright please contact us at:

repository@maastrichtuniversity.nl

providing details and we will investigate your claim.
}

Copyright and moral rights for the publications made accessible in the public portal are retained by the authors and/or other copyright owners and it is a condition of accessing publications that users recognise and abide by the legal requirements associated with these

- Users may download and print one copy of any publication from the public portal for the purpose of private study or research.

- You may not further distribute the material or use it for any profit-making activity or commercial gain

If the publication is distributed under the terms of Article $25 \mathrm{fa}$ of the Dutch Copyright Act, indicated by the "Taverne" license above, 


\section{Distractor Interference in Selective Reaching: Dissociating Distance and Grouping Effects}

\author{
Ron F. Keulen \\ Jos J. Adam \\ Department of Movement Sciences \\ Maastricht University \\ Maastricht, The Netherlands \\ Martin H. Fischer \\ Department of Psychology \\ University of Dundee, Scotland
}

\author{
Harm Kuipers \\ Department of Movement Sciences \\ Maastricht University \\ Maastricht, The Netherlands \\ Jelle Jolles \\ Department of Neuropsychology and Psychiatry \\ Maastricht University \\ Maastricht, The Netherlands
}

\begin{abstract}
In the present experiment, the authors sought to differentiate between a distance and a grouping explanation for the symmetric versus asymmetric patterns of distractor interfcrence in selective reaching. Participants $(N=16)$ pointed to a green target that appcared either with or without a red distractor. Target-distractor separation was manipulated within an array of 5 closely grouped stimulus boxes, and distractor interference (difference in performance between trials with and trials without a distractor) was measured in reaction time, movement time, percentage errors, and movement endpoints. Small distances $(5 \mathrm{~mm})$ between target and distractor yielded a symmetric pattern of interference, whereas latge distances $(20 \mathrm{~mm})$ yielded an asymmetric pattern, with more interference from near than from far distractors. Those findings support the distance account of distractor interference and refute the grouping account.
\end{abstract}

Key words: distractor interference, motor control, reference frames, selective attention

W hen individuals reach for a target, their response times are delayed by the presence of a distractor (i.e., an irrelevant stimulus) elsewhere in the visual display; that phenomenon is called distractor interference. According to an influential account of distractor interference in selective reaching (Tipper, Lortie, \& Baylis, 1992), both target and distractor compete for the control of action. The stimulus associated with an advantage in processing speed is likely to control the response. When that particular stimulus happens to be the desired target, the correct response will be evoked, and little or no interference occurs. If the advantage in processing speed is associated with the distractor, however, then the response associated with the distractor is activated. The motor system then requires inhibition to prevent responding to the distractor instead of to the target; that inhibition slows down reaching performance, and, consequently, interference effects are observed.

A good illustration of how processing speed can determine distractor interference is the proximity-to-hand effect
(Tipper et al., 1992), which refers to the phenomenon that a । distractor located between the start position of the responding : hand and the target creates a larger amount of interference than a distractor located beyond the target. The common ! observation that reaches to near objects are initiated faster . than reaches to far objects (Rosenbaum, 1980) provides an । explanation for that effect. In other words, near objects have । an advantage in processing speed compared with far objects । and thus are more likely to cause interference.

In a frequent explanation of the proximity-to-hand effect, , it is assumed that selective attention accesses an action (or hand)-centered frame of reference. According to that view, the amount of interference caused by a distractor is deter- . mined by its spatial relationship with the responding hand. . Until recently, the proximity-to-hand effect was found for target-distractor separations of at least $40 \mathrm{~mm}$ (Meegan \& Tipper, 1998, 1999; Pratt \& Abrams, 1994; Tipper et al., . 1992). Keulen, Adam, Fischer, Kuipers, and Jolles (2002) । investigated distractor interference for smaller target-distractor separations (i.e., 5 and $20 \mathrm{~mm}$ ). Leaving from a start । position, participants had to reach for a green target that . appeared in one of five potential stimulus locations (see : Figure 1). On some trials, a red, to-be-ignored distractor appeared at an adjacent location.

Keulen et al. (2002) found that the amount of interference in movement time was significantly greater with the small | than with the large target-distractor separation (10 and 5 : $\mathrm{mm}$, respectively). Furthermore, the proximity-to-hand । effect occurred only with the large target-distractor separa-

Correspondence address: Ron F. Keulen, Department of ! Movement Sciences, Maastricht University, $P O$ Box 616, 6200 ? $M D$ Maastricht, The Netherlands. E-mail address: , ron,keulen@bwunimaas.nt 


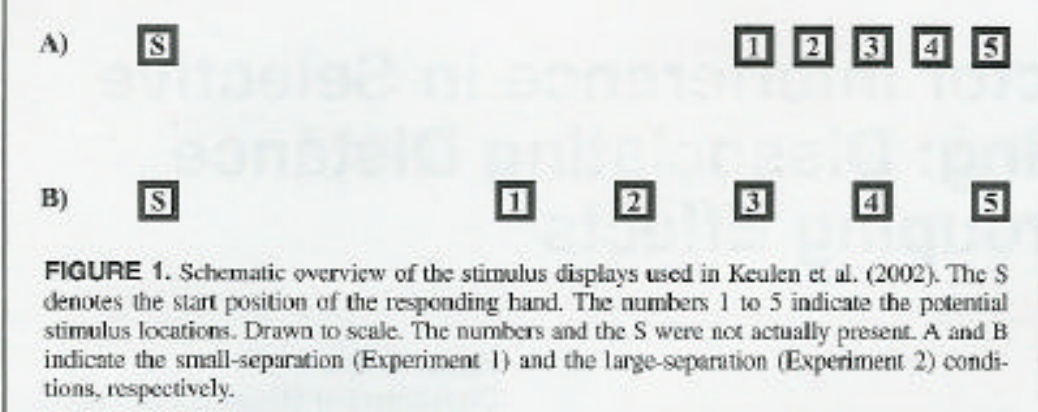

tion. With the small separation, the pattern of interference was symmetric, that is, equal amounts of interference from near distractors (i.e., distractors located berween the start position of the responding hand and the target) and from far distractors (i.e., distractors located beyond the target).' Keulen et al. suggested the possibility of an environmentcentered frame of reference to explain the symmetric pattern of interference, In an environment-centered frame of reference, locations of objects are coded with respect to other objects in the display (Danziger, Kingstone, \& Ward, 2001; Hinton \& Parsons, 1988). The possibility of an environment-centered frame of reference was further supported by the finding that when the target-distractor separation was small, the movement endpoints were biased away from the location of the distractor rather than away from the start position of the responding hand, as would be expected from an action-centered point of view. Support for the notion that the frame of reference that predominates is dependent upon the distance between target and distractor was provided by the finding that small target-distractor separations appeared to invoke an environment-centered frame of reference whereas large separations appeared to invoke an action-centered frame of reference.

Some caution seems appropriate in assigning a critical role to the distance between target and distractor in determining the relevant frame of reference, however. Perceptual grouping of the individual stimulus boxes might also account for the observed symmetry effect in the small-separation condition. That is, in the small-separation condition, the individual stimulus boxes might have been perceived as members of a group, whereas in the large-separation condition, the five stimulus boxes might have been perceived as separate, independent objects. That idea is based upon the Gestalt principle of proximity. That is, objects that are near to each other tend to unite and, as a result of that unification, to form perceptual groups. There are several lines of evidence suggesting that grouped objects are processed differently from independent objects. First, the global-preoedence phenomenon (e.g., Navon, 1977) indicates that the processing of a visual object is global to local; global properties (i.e., low spatial frequencies, viz, the whole) are processed first, followed by analysis of local properties (i.e, high spatial frequencies, viz., the constituting parts). Second, Fischer (1994) had participants bisect horizontal lines. Each line had two letters at its ends, with the spacing between letter and line being smaller one one side than on the other. Results showed that bisection judgments were shifted toward the side with the smaller spacing between letter and line. Apparently, the line and the nearby letter were perceived as a whole, making the line appear longer. A third line of evidence is that interference from distracting flankers in a letter-identification task is stronger when target and distractor are part of the same group than when they belong to different groups (Logan, 1996). Thus, there is evidence to suggest that perceptual grouping can affect information processing, and, therefore, grouping might have been a confounding factor in the Keulen et al. (2002) study.

To decide between a perceptual grouping and a distance explanation for the pattern of distractor interference in selective reaching, we conducted the present experiment. We used the same stimulus display with the small separation between the individual stimulus boxes that was used in Experiment 1 of the study by Keulen et al. (2002). A distractor could appear either directly adjacent to the target stimulus (i.e., one box to the left or to the right of the target stimulus - as in that study) or not adjacent (i.e., two boxes to the left or to the right of the target stimulus). In other words, we manipulated target-distractor separation within the array of closely grouped stimulus boxes. If the symmetry effect observed with the small target-distractor separation, as reported by Keulen et al. (2002), were caused by grouping of the stimulus boxes, one would expect symmetric interference for both small and lange target-distractor separations. If, however, the distance between target and distractor is responsible for the symmetry versus asymmetry in interference, then one would expect small and large separations to be associated with symmetric and asymmetric interference, respectively.

\section{Participants}

\section{Method}

Sixteen Maastricht University undergraduate students (8 men and 8 women) participated in the experiment. Their mean age was 22.9 years (range $=21-26$ years), All were paid a small amount of money (i.e., the equivalent of about 
\$4 U.S.), were right-handed, had normal or corrected-tonormal visual acuity, and were naive as to our purposes in the experiment.

\section{Apparatus and Stimuli}

Participants were tested individually in a quiet, dimly illuminated room. They were seated on a height-adjustable chair in front of a 43.2-cm (i.e., 17-in) Brilliance 107 video monitor (Philips, The Netherlands) that was equipped with an AccuTouch $\mathrm{C}$ touch screen (Elo TouchSystems, Fremont, CA). The monitor was placed in a normal, upright position, and participants made responses directly on the screen with the tip of their right index finger. Participants were positioned such that the body midline was in line with the start box on the left side of the display and the shoulder line was parallel to the monitor's screen. The stimulus display used in the experiment is schematically depicted in Figure 2(A). The start location and stimulus boxes were presented as squares in white outline on a black background and were permanently visible. The five stimulus boxes were arranged in a horizontal array spanning $7 \mathrm{~cm}$, with a distance of $5 \mathrm{~mm}$ between the individual stimulus boxes (side to side). The start box was located $14 \mathrm{~cm}$ to the left of that array (side to side).

The target stimulus was presented as a green square completely filling one of the stimulus boxes. The distractor stimulus was presented as a red square completely filling either a stimulus box directly adjacent to the target or a stimulus box next to an adjacent box. As a result, target-distractor separation was either $5 \mathrm{~mm}$ (distractor adjacent) or $20 \mathrm{~mm}$ (distrac- tor not adjacent]. A distractor could appear either to the left of the target (i.e, near distractor) or to the right of it (i.e., far distractor). In Figure 2 (B-F), five examples of experimental trials (with the target appearing at the third position) are schematically depicted.

All boxes were $10 \mathrm{~mm}$ wide and high. Note, however, that for defining an aiming error, we set the effective target width at $12 \mathrm{~mm}$; we did so in order to limit the number of errors (i.c., target misses). The touch screen was interfaced with an MS-DOS Pentium computer, which controlled stimulus presentation and recorded response times and response accuracy. Temporal resolution was $5 \mathrm{~ms}$, spatial resolution $0.1 \mathrm{~mm}$.

\section{Design}

Participants performed in one single session lasting about $25 \mathrm{~min}$. There were 310 test trials, preceded by 25 practice trials. Within the block of 310 test trials, there were 80 trials without distractor (that is, 20 for Target Location 3 and 15 for each of the remaining target locations) and 230 trials with distractor (15 for each target-distractor [T-D] combination with Targets 1,2,4, and 5; and 20 for each T-D combination with Target 3). The order of distractor and no-distractor trials was random. The block of test trials was interrupted twice by a 1 -min break.

\section{Procedure}

At the beginning of each trial, the start box turned green, indicating that the participants could move their fingertip to the green start box. Contact with the start box caused the

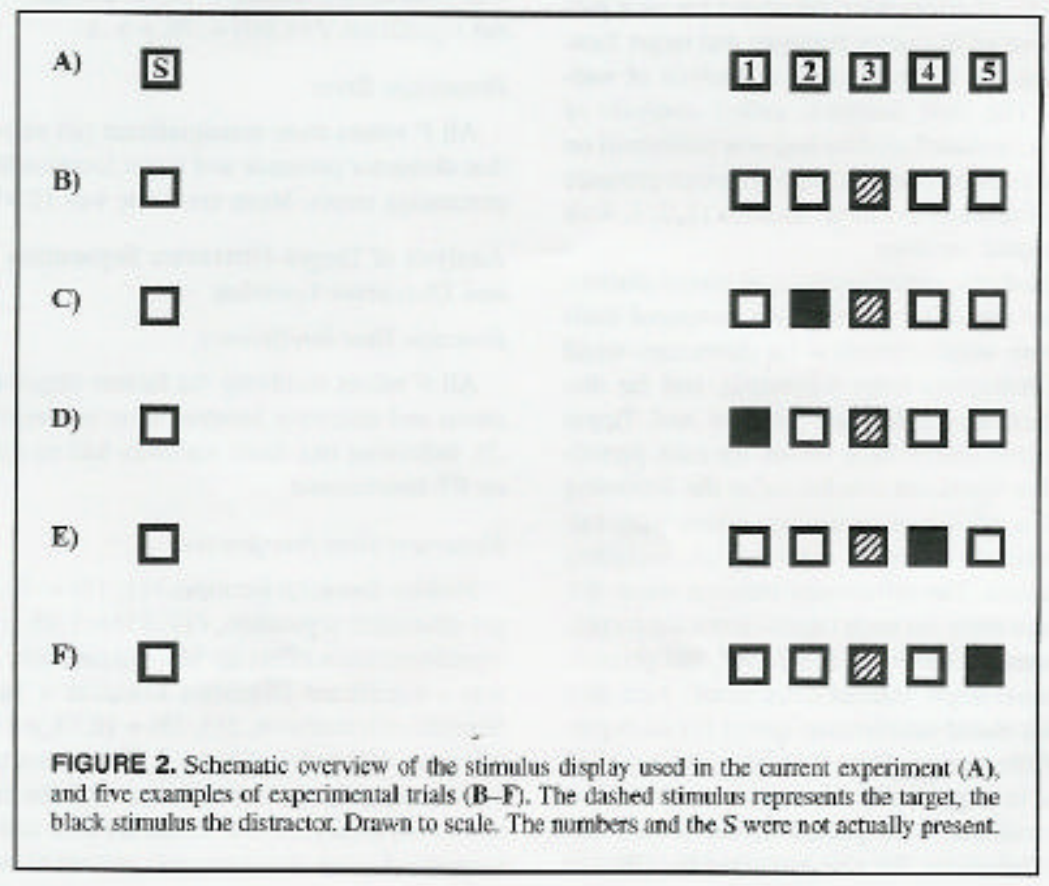


green light in the start box to disappear and the target stimulus (with or without distractor) to appear immediately and to remain on until the response was completed. Participants were informed that on each trial a green light would appear in one of the five stimulus boxes and that on some trials a red light would appear in a different box. They were instructed to contact the green target stimulus as quickly and accurately as possible while ignoring the red distractor stimulus. One second after completing the aiming response, the stimulus boxes were cleared and the start box turned green again, signaling the start of the next trial, which the participants could initiate at will. The computer presented a visual-feedback signal if the participant failed to hit the target box or if the start box was released too soon (that is, within $100 \mathrm{~ms}$ after target presentation). In addition, the computer generated a visual error signal if the participant failed to contact the start box accurately. In that case, the trial was repeated.

We calculated two measures of response time: (a) reaction time (RT), which was measured from the time the target stimulus appeared to the time the start box was released; and (b) movement time (MT), which was measured from the time the start box was released to the time the target box was pressed.

\section{Analysis}

RTs below 100 ms were considered anticipations and were excluded from data analyses; 4.15 of the trials were removed on the basis of that criterion ( $3.4 \%$ of the no-distractor trials and $4.4 \%$ of the distractor trials). For the remaining trials, RT, MT, and proportions of errors were calculated for each participant as a function of distractor presence and target location. We performed two different kinds of analysis of vanance (ANOVA). The first analysis, called anolysis of distractor presence, included all data and was performed on mean RT, MT, and percentage errors, with distractor presence (with vs, without distractor) and target location $(1,2,3,4$, or 5) as within-participant variables.

In the second analysis, called analysis of target-distractor separation and distractor location, we compared trials with near distractors-small separation, far distractors-small separation, near distractors-large separation, and far distractors-large separation. Following Meegan and Tipper (1998), we calculated interference scores for each participant in each of the distractor conditions in the following manner. Mean RTs, MTs, and percentage errors were calculated for each target-distractor combination, including target-only conditions. The differences between mean RT, MT, and percentage error for each target-distractor combination and its respective control (i.e., RT, MT, and percentage error to the same target without a distractor) were then calculated. We calculated interference scores for each participant in each distractor condition by taking a mean of all difference scores in a particular distractor condition; the means in each condition were pooled across several target-distractor combinations. We also examined the effect of target-distractor separation and distractor location on the spatial endpoints of the movements. In particular, we assessed biases in the horizontal and vertical dimensions relative to the exact center of the target box in terms of the constant error (CE). Again, interference scores were calculated following the procedure previously described.

Whenever appropriate, we adjusted the tests for heterogeneity of variance and covariances by using the HuynhFeldt corrected significance values, We carried out post hoc analyses by performing modified $t$ tests, using the Bonferroni method to adjust the $p$ values. To determine statistical significance, we used an alpha level of .05 .

\section{Results}

\section{Analysis of Distractor Presence}

\section{Reaction Time}

All $F$ values were nonsignificant (all $p s>4$ ), indicating that target location and distractor presence had no effect on RT. Mean RT was 186 ms.

\section{Movement Time}

There was a significant main effect of distractor presence, $F(1,15)=27.59, p<.001$, indicating a mean interference effect of $16 \mathrm{~ms} M \mathrm{ss}=429 \mathrm{vs}, 413 \mathrm{~ms}$ for trials with and without distractor, respectively). There also was a main effect of target location, $F(4,60)=31.94, p<.001$, indicating longer MTs for targets located farther away from the start position of the responding hand $(M s=394,414,421$, 434, and $442 \mathrm{~ms}$ for Targets 1, 2, 3, 4, and 5, respectively). The Distractor Presence $\times$ Target Location interaction was not significant, $F(4,60)=.76, p>.5$.

\section{Percentage Error}

All $F$ values were nonsignificant (all $p s>5$ ), indicating that distractor presence and target location had no effect on percentage errors. Mean error rate was $12.9 \%$.

\section{Analysis of Target-Distractor Separation and Distractor Location}

\section{Reaction Time Interference}

All $F$ values involving the factors target-distractor separation and distractor location were nonsignificant (all $p \mathrm{~s}>$ .2), indicating that those variables had no differential effect on RT interference.

\section{Movement Time Interference}

Neither distractor location, $F(1,15)=.75, p>.3$, nor target-distractor separation, $F(1,15)=1.95, p>.1$, showed a significant main effect on MT interference. However, there was a significant Distractor Location $\times$ Target-Distractor Separation interaction. $F(1,15)=10.73, p<.01$. That interaction is depicted in Figure 3. The interaction indicated a symmetric pattern of interference with the small target-distractor separation (16 vs. $19 \mathrm{~ms}$ for near and far distractors. respectively) but an asymmetric pattern of interference with 

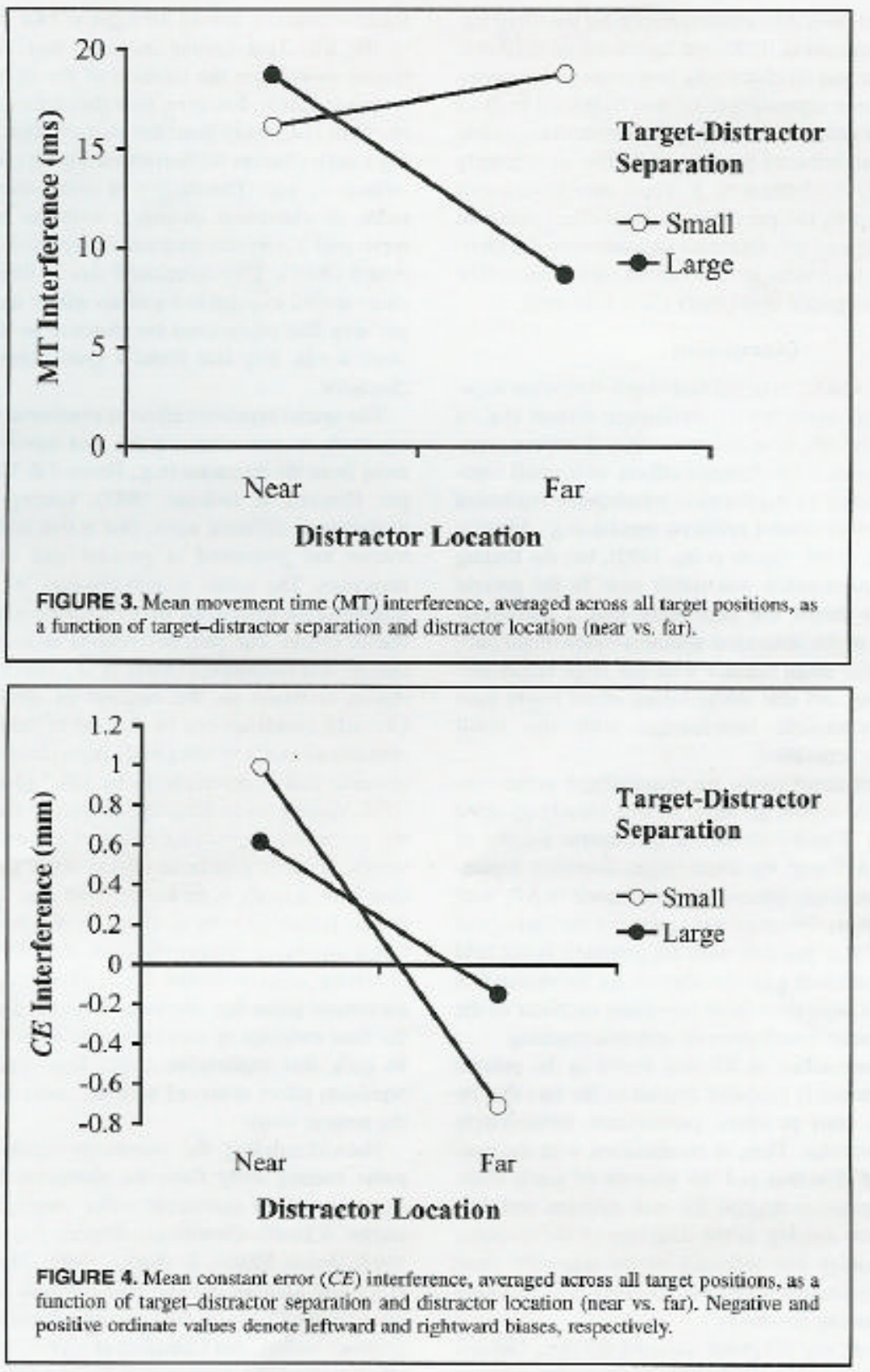

the large separation (19 vs, $9 \mathrm{~ms}$ for near and far distractors. respectively). Thus, a proximity-to-hand effect materialized, but only for the large target-distractor separation.

\section{Percentage Error Interference}

All $F$ values involving the factors target-distractor separation and distractor location were nonsignificant (all $p \mathrm{~s}>$
.2), indicating no differential effects on percentage error interference.

\section{Movement Endpoint Interference}

There was a significant Distractor Location $x$ Target-Distractor Separation interaction, $F(1,15)=12.49$, $p<.005$ (see Figure 4). The interaction indicated that the 
pattern of spatial diversion was symmetric for the small target-distractor separation $(0.99 \mathrm{~mm}$ rightward vs. $0.70 \mathrm{~mm}$ leftward for near and far distractors, respectively) but asymmetric for the large separation (0.61 mm rightward vs. 0.15 $\mathrm{mm}$ leftward for near and far distractors, respectively). Note that the 0.15 -mm leftward bias did not differ significantly from zero, $t(15)=-1.06, p>3$. Thus, also in terms of movement endpoint, the proximity-to-hand effect occurred only with the large target-distractor separation. In the vertical dimension, there were no differential biases; all conditions showed an upward bias (mean $C E=0.69 \mathrm{~mm}$ ).

\section{Discussion}

Keulen et al. (2002) manipulated target-distractor separation and found asymmetric interference effects (i.e., a proximity-to-hand effect) with large target-distractor separations but symmetric interference effects with small separations. The finding of asymmetric interference replicated the results found in several previous reports (e.g., Meegan \& Tipper, 1998, 1999; Tipper et al., 1992), but the finding of symmetric interference was ruther new. In the present experiment, we tested the possibility that a perceptual grouping effect of the individual stimulus boxes might have occurred with the small but not with the large target-distractor separation and that the grouping effect might have caused the symmetric interference with the small target-distractor separation.

In the current experiment, we manipulated target-distractor separation within an array of five closely grouped stimulus boxes. Results showed a symmetric pattern of interference in MT with the small target-distractor separation but an asymmetric pattern of interference in MT with the large separation. Those results replicated the findings of Keulen et al. (2002), but now with the grouping factor held constant. That outcome provides support for the notion that target-distractor separation is an important mediator of the pattern of distractor interference in selective reaching.

No interference effect in RT was found in the present study. That outcome is probably related to the fact that by depressing the start position, participants immediately called up the stimulus. That, in combination with the constant movement direction and the absence of catch trials, allowed participants to depress the start position and then immediately start moving in the direction of the stimulus boxes. That strategy was reflected by the relatively short RTs. Thus, in the present paradigm, RT scemed to be a poor indicator of planning processes.

Note, morcover, that the grand mean for RT (i.e., 186 ms) was closer to what one would expect in a simple reaction time paradigm than to what one would expect in a five-choice situation. However, RTs for reaching movements are independent of the number of response choices (Favilla, 1996).

In the present experiment, the movement endpoints displayed a symmetric pattern of interference with the small separation but an asymmetric pattem with the large separation. More specifically, with the small separation, near dis- tractors caused a bias to the right and far distractors a bias to the left. That finding indicates that movements were biased away from the location of the distractor. With the large separation, however, near distractors caused a bias to the right (i.e., away from the start position of the responding hand), whereas far distractors did not cause a significant amount of bias. The finding of symmetric interference in terms of movement endpoints with the small separation replicated a similar observation reported by Fischer and Adam (2001). They concluded that in their study, participants tended to point to locations within the prescribed target area that maximized the distance to the distractor. In other words, they also found a spatial bias away from the distractor.

The spatial repulsion effect is consistent with the finding reported in numerous articles that movement paths veer away from the distractor (e.g. Howard \& Tipper, 1997; Tipper, Howard, \& Jackson, 1997). Veering away has been explained in different ways. One is that both target and distractor are processed in parallel and evoke competing responses. The motor system resolves the competition by inhibiting the competing internal representations of the distractor object. The path deviation is interpreted as a reflection of that inhibition (Tipper et al., 1997). Another explanation is based on the concept of obstacle ayoidance. Obstacle avoidance can be defined as "moving around the obstacle so as not to bring body parts eloser than a preferred distance that is perceived to be safe" (Tresilian, 1998, p. 356). Veering away from the distractor, then, is caused by the perceived obstructing effect of the distractor. In other words, obstacle avoidance effects oecur not only when the distractor actually is an obstacle but also when a distractor is only perceived to be an obstacle. People attempt to maintain a minimum distance between their limb segments and distractor objects within the workspace, thus leading to movement paths that veer away from the distractor. Because the final endpoint of a movement is often closely related to its path, that explanation might also apply to the spatial repulsion effect observed with the movement endpoints in the present study.

Notwithstanding the numerous reports of movement paths veering away from the distractor, there have been some reports of movement paths veering toward the distractor (Chieffi, Gentilucci, Allport, Sasso, \& Rizzolatti, 1993; Welsh, Elliott, \& Weeks, 1999). However, Welsh et al. (1999) used an indirect pointing task (moving a cursor on a computer screen by moving a handheld mouse on a graphics tablet), and Chieffi et al. (1993) found the veering effect toward the distractor only in a patient with a right parietal lesion. In the present study, all participants were normal, healthy adults who performed a direet reaching movement, as were the participants in the aforementioned studies in which movement paths were found to veer away from the distractor:

The MT and movement endpoint data suggested that small and large target-distractor separations appear to 
invoke an environment-centered and an action-centered frame of reference, respectively. That observation is consistent with the idea that multiple frames of reference can be accessed when performing a reaching response. How can that be explained?

A possible explanation is focused on the idea that the distance between target and distractor determines whether target and distractor are perceived as a group or as separate objects. Note that that explanation is different from the grouping account mentioned in the introductory comments. That is, although the focus in the grouping account is on the spatial organization of the individual stimulus boxes, the following explanation relates to the specific organization of target and distractor.

According to that idea, with small target-distractor separations, the complex of target and distractor is likely to be perceived as a single, large "compound" stimulus. A response will then be directed toward the compound stimulus. When the vicinity of that stimulus is reached, the actor has to discriminate between target and distractor in order to terminate the movement accurately at the target. After selection of the target has taken place, a corrective movement is made toward the target. That process of selection and fine-tuning is time-consuming and slows down reaching for the target. Because the target and the distractor are close together, the duration of the reguired corrective movement will not differ substantially for trials with near and those with far distractors. As a result, a symmetric pattem of interference is observed.

With the large separation, however, target and distractor are most likely perceived as two separate, independent objects. It is therefore plausible that a response heading for the nearest stimulus is initially prepared. When a near distractor accompanies the target, the stimulus nearest to the start position of the hand is the distractor. When approaching that stimulus, identification takes place. When the distractor is then recognized as such, the tendency to terminate movement at the distractor has to be actively inhibited, and movement toward the target has to be continued. That inhibition interrupts the ongoing response and slows down movement time towand the target. However, when a far distractor accompanies the target, the target is nearest to the start position. When identification takes place approaching the first stimulus, and the target is recognized as such, the movement will terminate at the target. A far distractor then will not or will minimally interfere with target-directed reaching. That explains the asymmetric partem of interference.

In sum, the present pattern of results suggests that participants were accessing different frames of reference in the small- and large-separation conditions (environment-centered and action-centered, respectively). However, one might argue that the disappearance of the proximity-to-hand effect in the small-separation condition does not necessarily imply that an environment-centered rather than an actioncentered frame of reference is accessed. Assuming that the action-centered region extends slightly beyond the target, one might argue that far distractors with a 5-mm target-distractor separation are included in that region, whereas far distractors with a 20 -mm target-distractor separation are not included. That line of reasoning would also explain the symmetric and asymmetric patterns of interference in the small- and large-separation conditions. However, that alternative explanation cannot account for the movement endpoint datu; that is, the observation that in the small-separation condition the movement endpoints veered away from the location of the distractor and not away from the start location of the responding hand is at odds with an actioncentered account,

In conclusion, with small target-distractor separations, interference is determined by the relationship between target and distractor (environment-centered). With large target-distractor separations, however, the relationship between target, distractor, and the start position of the hand is critical (action-centered). In the present study, we showed that those findings are true also when target-distractor separation is manipulated within an array of closely grouped stimulus boxes.

\section{ACKNOWLEDGMENT}

We thank Digby Elliott and Daniel Meegan for their constructive comments on an earlier version of this article.

\section{NOTE}

1. The movements reported by Keulen et al, (2002) as well as the movemeats in the present study were from left to right, whereas in the study of Tipper et al. (1992) movements were made cither away from or toward the body.

\section{REFERENCES}

Chieffi, S., Gentilucei, M., Allport, A., Sasso, E, \& Rizzolatti, G. (1993). Stady of selective reaching and grasping in a paticot with unilateral parietal lesion. Dissociated effects of residual spatial neglect. Brain, H/6, 1119-1137.

Danziger, S. Kingstone, A., \& Ward, R. (2001). Environmentally defined frames of reference: Their time course and sensitivity to spatial cues and attention. Joumal of Experimental Psychology: Human Perception and Performance, 27, 494-503.

Favilla, M. (1996), Reaching movements: Programming time course is independent of choice number. Newoneport, 7, $2629-2634$

Fischer, M. H. (1994). Less attention and more perception in cued line bisection. Brain and Cognition, 25, 24-33.

Fischer, M. H., \& Adam, J. J. (2001). Distractor effects on pointing: The role of spatial layout. Euperimental Brain Research, $136,507-513$.

Hinton, G. E. \& Parsons, L. M. (1988). Scene-based and viewercentered representations for comparing shapes. Cognition, 30, 1-35.

Howard, L. A., \& Tipper, S. P. (1997). Hand deviations away from visual cues: Indireet evidence for inbibition. Experimental Brain Researchi, $173,144-152$.

Keulen, R. F., Adam, J. J., Fischer, M. H., Kuipers, H, \& Jolles, J. (2002). Selective reaching: Evidence for multiple frames of reference. Joumal of Experimental Psychology: Hunan Perception and Perfomance, 28, 515-526.

Logan, G. D. (1996). The CODE theory of visual attention: An integration of space-based and object-based attention. Psycho- 
Logical Review, 103, 603-649.

Meegan, D. V., \& Tipper, S. P. (1998). Reaching into cluttered visual environments: Spatial and temporal influences of distracting objects. The Quarterly Jowrial of Experimentai Psychology, 51, 225-249.

Meegan, D, V. \& Tipper, S, P. (1999) Visual search and targetdirected action. Journal of Experimental Psychology: Human Perception and Performance, 25, 1347-1361.

Navon, D. (1977). Forest before trees: The precedence of global features in visual perception. Cognirive Psychology, 9, 353-383.

Pratt, J., \& Abrams, R. A. (1994). Action-centered inhibition: Effects of distractors on movement planning and execution. Human Movement Science, 13, 245-254.

Rosenbaum, D. A. (1980). Human movement initiation: Specification of arm, Girection, and extent Joumal of Experimenial Psy. chology: General, 109, $444,474$.
Tipper, S. P. Howard, L. A., \& Jackson, S, R. (1997). Selective reaching to grasp: Evidence for distractor interference effects. Wisual Cognition, 4, 1-32,

Tipper, S. P., Lortie, C., \& Baylis, G. C. (1992). Selective reaching Evidence for action-centered attention. Joumal of Experimental Psychology: Human Perception and Performance, 18 $891-905$.

Tresilian, J. R. (1998). Attention in action or obstruction of movement? A kinematic analysis of avoidance behavior in prehension, Experimental Brain Research, 120, 352-368.

Welsh, T. N., Elliot, D., \& Weeks. D. J. (1999). Hand deviations toward distractors, Evidence for response competition. Experi. mental Brain Research, 127, 207-212.

Submitted February 25, 2002

Revised July 8, 2002 